\title{
'Codeine is my companion': misuse and dependence on codeine containing medicines in Ireland
}

\author{
M. C. Van Hout ${ }^{1 * *}$, A. Horan ${ }^{2}$, K. Santlal ${ }^{3}$, E. Rich ${ }^{4}$ and M. Bergin ${ }^{1}$ \\ ${ }^{1}$ School of Health Sciences, Waterford Institute of Technology, Waterford, Ireland \\ ${ }^{2}$ Arbour House, HSE Addiction Services, Cork, Ireland \\ ${ }^{3}$ National Drug Treatment Centre, Dublin, Ireland \\ ${ }^{4}$ Alcohol, Tobacco and Other Drug Abuse Research Unit, South African Medical Research Council
}

\begin{abstract}
Objectives. Global concern around over the counter availability of codeine containing products and risk of misuse, dependence and related harms are evident. A phenomenological study of lived experiences of codeine misuse and dependence was undertaken in Ireland, following the Pharmaceutical Society of Ireland's 2010 guidelines for restricted supply of non-prescription codeine containing products.
\end{abstract}

Methods. In-depth interviews were conducted with a purposive sample of adult codeine misusers and dependents $(n=21)$, both actively using, in treatment and in recovery. The narratives were analysed using the Empirical Phenomenological Psychological five-step method (Karlsson, 1995). A total of 10 themes with 82 categories were identified. Two concepts at a higher level of abstraction above the theme-level emerged during the final stage of analysis. The concepts identified were 'emotional pain and user self-legitimization of use' and 'entrapment into habit-forming and invisible dependent use'. These concepts were reported in different ways by a majority of participants.

Results. Findings are presented under the following themes: (1) profile and product preferences; (2) awareness of habit forming use and harm; (3) negotiating pharmacy sales; (4) alternative sourcing routes; (5) the codeine feeling; (6) the daily routine; (7) acute and chronic side effects; (8) social isolation; (9) withdrawal and dependence and (10) help-seeking and treatment experiences.

Conclusions. There is a public health and regulatory imperative to develop proactive responses tackling public availability of codeine containing medicines, risk minimisation in consumer self-treatment for pain, enhanced patient awareness of potential for habit forming use and its consequences and continued health professional pharmacovigilence.

Received 3 July 2015; Revised 2 October 2015; Accepted 12 November 2015; First published online 8 December 2015

Key words: Codeine, dependence, opiate.

\section{Introduction}

Contemporary research highlights global concerns around misuse of prescribed and over the counter codeine as the most commonly consumed opiate (Van Hout et al. 2014). Global demand for codeine preparations has increased by $27 \%$ in the previous decade (INCB, 2012). Prescription of codeine for pain relief is increasing in Europe (Fredheim et al. 2009). Misuse of non-prescription codeine containing medicines is increasing, particularly where available in over the counter available combination products (McAvoy et al. 2011) amid calls for stronger regulatory responses to tackle over the counter codeine analgesic misuse (Tobin et al. 2013). Quantifying the extent of such misuse centres on varies by country surveillance and methodological

* Address for correspondence: M. Claire Van Hout, 107 School of Health Sciences, Waterford Institute of Technology, Waterford, Ireland.

(Email: mcvanhout@wit.ie) approaches utilised, and is complicated by public availability and the hidden and heterogeneous characteristics of codeine misuse and dependence (UNODC, 2011, 2013).

Codeine or 3-methylmorphine is a methylated morphine derivative occurring naturally with morphine in the poppy seed. It is a short acting, weak to mid-range opiate and commonly used to manage mild to moderate pain in adults as well as for its antitussive and antidiarrheal properties (Tremlett et al. 2010). Recommended daily oral dose for adults is between 30 and $60 \mathrm{mg}$ every 4 hours and to a maximum of $240 \mathrm{mg}$ (Derry et al. 2013). Conversion to morphine by endogenous enzymes causes altered perceptions and emotional responses to pain (Kelly \& Madadi, 2012). Administration of codeine incurs common opioid-typical side effects, which include sedation, euphoria and constipation. Of note is that patient responses to codeine and risk of intoxication vary due to genetic variations in metabolism (Ingelman-Sundberg et al. 2007; Zhou, 2009). 
Codeine has an identified abuse potential evident in drug administration research (Babalonis et al. 2013), and multiple reportings of case dependence (Sproule et al. 1999; Frei et al. 2010). Tolerance develops on repeated administration of codeine within a relatively short time frame, with increasing doses whether legitimate (therapeutic) or intoxicating (non-therapeutic) increasing likelihood of neuro-adaptation and dependence symptomatology (Dobbin \& Tobin, 2008; Nielsen et al. 2010; Reed et al. 2011). Excessive and/or long-term consumption of combination products containing additives (ibuprofen, paracetamol) carries risk of adverse health consequences such as nephro-toxicity, hypokalaemia, gastrointestinal haemorrhage, acute haemorrhagic necrotising pancreatitis and brain damage, often occurring in individuals with no history of substance use disorders or co-morbidity (for a comprehensive review of clinical case presentations see Van Hout et al. 2014). Furthermore, misuse of codeine may be an iatrogenic cause of psychiatric disturbances (Manchia et al. 2013) with paranoid psychosis frequently associated with codeine cough mixture abuse and symptoms of anxiety and depression occurring with long-term use (Romach et al. 1999; Dobbin \& Tobin, 2008).

Within trajectories of codeine misuse and dependence, a wide ranging profile of codeine user exists; for example, the elderly (Roumie \& Griffin, 2004; Agaba et al. 2004); youth (Elwood, 2001; Lam \& Shek, 2006; Peters et al. 2003, 2007a, 2007b, 2007c; Shek \& Lam, 2006, 2008; Ford, 2009; Lao et al. 2010; Wilson et al. 2010; Tang et al. 2012; Agnich et al. 2013); parents (Allotey et al. 2004); students (Acocella, 2005); pharmacy customers (Sweileh et al. 2004; Albsoul-Younes et al. 2010); drug and psychiatric treatment patients (Agyapong et al. 2013); addiction treatment patients (Akram \& Roberts, 2003; Myers et al. 2003; Yang \& Yuan, 2008; Cohen et al. 2009; Thekiso \& Farren, 2010; Nielsen et al. 2011; Cooper, 2013b) and internet drug forum users (Van Hout, 2015) each with their own motives, patterns and outcomes for use. However, there is a lack of consensus around a definition of misuse of pharmaceutical opioid narcotics (Barrett et al. 2008; Casati et al. 2012; Cooper, $2013 a$ ) with broad misuse of pharmaceutical definitions including incorrect but legitimate use for medical purposes; use outside of acceptable medical guidelines when self-medicating at higher doses and for longer than advised; use for reasons other than for the instructions on the label or the intended purpose; recreational use for intoxication purposes; and where risks and adverse consequences outweigh the benefits (Nielsen et al. 2008; Casati et al. 2012).

Prevalence of codeine misuse and dependence is difficult to monitor and quantify, and relies on indicators based on surveillance of treatment cases for codeine dependence (Pates et al. 2002; Skurtveit et al. 2011; Roussin et al. 2013). Codeine dependence is generally treated in residential detoxification programmes, with opiate substitution therapy (methadone or buprenorphine) or lofexidine in community detoxification (Frei et al. 2010; Mattick et al. 2008; Kelly \& Madadi, 2012). Clinical profiles vary, with majority representation of those in middle to late age, females, poly substance users, alcohol users and those with underlying psychiatric conditions (Myers et al. 2003; Johansson et al. 2003; Thekiso \& Farren, 2010; Robinson et al. 2010; Agyapong et al. 2013). Other studies report on characteristics of individuals dependent on codeine as young, with lower levels of education and employment, reporting chronic pain, family history of problematic substance use and with greater proportions female when compared with other cohorts of opiate dependent individuals (Nielsen et al. 2011). For those seeking treatment for codeine dependence in Australia, primarily older females are reported which distinguish from other groups of opiate dependents, although this trend is now changing to reflect younger males (Nielsen et al. 2015).

Recent formal drug treatment data involving codeine misuse and dependence indicates that $1.9 \%$ of persons in drug treatment in Ireland (personal communication from the National Drug Treatment Reporting System) reported codeine as a primary or secondary drug of abuse in the time period 2008-2012. Irish studies suggest that misusers of codeine are more likely to be male, older, with co-morbid psychiatric, physical and poly substance illness and with a longer drug dependence history (Cohen et al. 2009; Thekiso \& Farren, 2010). The covert nature of codeine misuse and dependence with the co-occurrence of serious co-morbidity and complexity of cases highlights the need for further research within an Irish context (Thekiso \& Farren, 2010). This is timely given the changes employed by the Irish pharmacy regulator (Pharmaceutical Society of Ireland) in 2010 to regulate safe supply of non-prescription combination products containing codeine and paracetamol, aspirin or ibuprofen for supply only as 'second line' products for the treatment of pain relief; with comprehensive patient advice provided around correct use for short-term use (no longer than 3 days and with products in-accessible to the public for self-selection). Arguably, more stringent regulations for safe supply could potentially reduce misuse of codeine medicines among psychiatric patients (Agyapong et al. 2013).

Therefore, the aim of this study is to gain an understanding of individual and collective experiences of codeine use, pathways to misuse and dependence and experiences of treatment services in Ireland following the introduction of such guidelines for the safe supply of over the counter codeine-based products. 


\section{Methods}

In-depth interviews were conducted with a purposive sample of adult codeine misusers and dependents $(n=21)$, both actively using, in treatment and in recovery. In order to distinguish between dependent and non-dependent use, participants completed the severity of dependence screener (SDS) (Gossop et al. 1995), which is a five-item questionnaire, with scores of over five indicating dependence use in the past 12 months. Each item addresses the psychological components of dependence, particularly relating to lack of control, preoccupation and anxieties about the drug used. Items are scored along a four-point scale, and aggregated, with a high score indicating a high level of dependence. Nielsen et al. (2010) in their research on codeine dependence in Australia have suggested a SDS cut off of five has reasonable sensitivity and specificity in identifying problematic users of codeine containing products.

Recruitment was facilitated by selected gatekeepers (specialist medical doctors) within the National Drug Treatment Reporting System. These gatekeepers assisted in the recruitment of individuals in the centres by identifying codeine misusers and dependent patients and providing information on the study to these patients before their participation in the study. All participants received an information sheet and completed a consent form, which was explained verbally by the interviewer before the interview. All participants were assured of confidentiality and anonymity, and that they could withdraw from the study if they so wished. Interviews lasted between 30 and 90 minutes and were audio-recorded with permission. Participants' anonymity was protected by removal of personal identifiers (Wilkinson \& Thelwall, 2011).

Audio-files were transcribed and transferred to a Word document that was password-protected and analysed in accordance with the Empirical Phenomenological Psychological (EPP) five-step method (Karlsson, 1995) (Table 1). This method is underpinned by Husserl's (1970) phenomenology theory and strongly aligned with Giorgi's (1997) principles by facilitating the interpretation of meaning of lived phenomena, in this instance the 'life world' experience of codeine misuse and dependence. It is an analytic process based on the interpretation of a dialectic understanding of the hermeneutical circle and its dynamic movement between a sense of the whole picture and of its parts in order to achieve an incremental understanding of the lived phenomenon (Karlsson, 1995). The EPP method ensures high validity by emphasising an open, non-judgemental and bias free attitude in interpretation of the data and respect of
Table 1. Empirical Phenomenological Psychological five-step method (Karlsson, 1995)

Step 1 The data file was read three times so as to familiarise identify psychological phenomena and achieve an overview of the codeine misuse phenomenon in an unbiased and open manner, and in the absence of any specific hypothesis. Theoretical reflection was withheld at this step

Step 2 The text was then divided into smaller meaning units (MU), without regard to syntax, included whole paragraphs to single words, and each time a new meaning, focus or topic was introduced

Step 3 All MUs were subsequently transformed from the participants wording and restated in order to present the significant and implicit meaning of the codeine misuse phenomena in objectivised terms. In order to obtain interpretative validity (Maxwell, 1992), considerable efforts were made to ensure respect of the participants' experience

Step 4 The restated MUs were categorised by repeated consultation with the raw data, scrutinising that the category itself was maintained, the understanding of what the phenomenon is (noema) and how it is expressed (noesis) and by considering specific characteristics and similarities in this codeine misuse phenomena

Step 5 The generated categories were then part of an abstraction process to create more general and overarching themes through the patterns identified within related categories. A total of 10 themes with 82 categories emerged from the analysis

the experiential perspectives of the individuals (Maxwell, 1992). It aims to explore subjective experiences by 'describing the meaning-structure of a psychological phenomenon. This method yields descriptive results, which disclose the intentional relationship between the subject and the object of experience' (Karlsson, 1995: 78).

Table 2 illustrates the emergent 10 themes and 82 categories. During the final step in the analysis process, two concepts at a higher level of abstraction above the theme-level (Table 2) emerged. These concepts centred on the interplay between 'emotional pain and user self-legitimization of use' and 'entrapment into habit-forming and invisible dependent use'. For example 'Pain killers are not just for what is written on the back of the pack, muscle pain, period pain, toothache, migraine, they should add also pain relief from anxiety, depression and heartache'. and 'Codeine is my invisible friend It's a very powerful drug, I never expected it to take me where it did, which was the highest of highs and the lowest of lows'. All raw data were re-read with these two concepts described by a majority participants in distinct ways. 
Table 2. Themes and categories

\begin{tabular}{|c|c|}
\hline Theme & Category \\
\hline $\begin{array}{l}\text { Profile and product } \\
\text { preferences }\end{array}$ & $\begin{array}{l}\text { 1. Minority prior experience of illicit drugs such as heroin, cannabis, cocaine and ecstasy. } \\
\text { 2. Opinions around combining codeine medicines with alcohol and illicit drugs mixed with regard to } \\
\text { desired intoxication outcomes. } \\
\text { 3. Codeine combined with alcohol, particularly at night time. } \\
\text { 4. Preference for misuse of Nurofen }+{ }^{\circledR} \text {, with some displacement during times of unavailability to use of } \\
\text { other codeine containing medicines, both non-prescription and precribed (Solpedeine }{ }^{\circledR}, \text { Feminex }{ }^{\circledR} \text {, } \\
\left.\text { Solpadol }{ }^{\circledR}, \text { Tylex }{ }^{\circledR}, \text { Codinex }{ }^{\circledR}\right) \text {. } \\
\text { 5. Use of prescribed distalgesic containing codeine. } \\
\text { 6. The effect of Nurofen }+{ }^{\circledR} \text { described as optimal for intoxication. } \\
\text { 7. Solpedeine }{ }^{\circledR} \text { observed to contain too much caffeine, with unpleasant symptoms on excessive use. } \\
\text { 8. Feminex }{ }^{\circledR} \text { observed to cause nausea. } \\
\text { 9. Consumption of tablets favoured. }\end{array}$ \\
\hline $\begin{array}{l}\text { Awareness of habit } \\
\text { forming } \\
\text { use and harm }\end{array}$ & $\begin{array}{l}\text { 1. Lack of awareness of addictive potential of codeine containing medicines and the harms related to } \\
\text { additives such as ibuprofen and paracetamol. } \\
\text { 2. Few read product information leaflet. } \\
\text { 3. Health professionals (users) aware of additive potential and related harms. } \\
\text { 4. Lack of public awareness and televised product marketing as painkiller by companies. } \\
\text { 5. Need for greater information provision around use, and risks of misuse from prescribing doctors } \\
\text { relating to codeine containing medicines. } \\
\text { 6. Low awareness of intoxication potential of codeine containing medicines for recreational purposes. } \\
\text { 7. Consultation of the internet to learn more about which products contained codeine when actively } \\
\text { misusing. } \\
\text { 8. Low reporting of tablet splicing of Nurofen }+{ }^{\circledR} \text { and cold water extraction. } \\
\text { 9. Low reporting of consumption of food before consumption of large amounts of tablets. } \\
\text { 10. Despite awareness of habit forming use and harm, while actively misusing, denial and inability } \\
\text { to stop. }\end{array}$ \\
\hline $\begin{array}{l}\text { Negotiating } \\
\text { pharmacy sales }\end{array}$ & $\begin{array}{l}\text { 1. Accessing of pharmacies as primary route to securing codeine containing medicines. } \\
\text { 2. Accessing multiple pharmacies in different locations and at intervals in order to circumvent } \\
\text { suspicion. } \\
\text { 3. Few purchased over the internet. } \\
\text { 4. Awareness of deception and overt manipulation of pharmacy and medical staff. } \\
\text { 5. Intense discomfort relating to the thought processes of seeking and securing sufficient supplies of } \\
\text { codeine containing medicines. } \\
\text { 6. Awareness of regulation for restricted sale of codeine containing medicines. } \\
\text { 7. Use of pre-rehearsed scripts when responding to pharmacist interrogation. } \\
\text { 8. Appearances in securing a successful sale varied. } \\
\left.\text { 9. Asking for a female specific codeine containing medicine (Feminex }{ }^{\circledR}\right) \text { sometimes secured a } \\
\text { successful sale. } \\
\text { 10. Instances when pharmacy staff recognised the customer, led to purchasing of alternative products or } \\
\text { simply leaving the store. } \\
\text { 11. Asking friends to purchase on their behalf. } \\
\text { 12. Pharmacist intervention at point of sale triggering thoughts and realisations around misuse. }\end{array}$ \\
\hline
\end{tabular}

Alternative sourcing routes
1. Alternative methods of sourcing codeine containing medicines centred on diversion via prescriber, street and family routes.

2. Border travel to jurisdictions with less stringent regulations around pharmacy supply (Spain and Northern Ireland).

3. Accessing surplus codeine containing medicines from friends and family, who did not utilise their repeat script.

4. Street diversion via purchasing from medical card patient in receipt of repeat scripts and not utilising the medicine.

5. Manipulation of doctors for early and repeat prescriptions.

6. Consulting multiple doctors and forging of scripts.

7. Health service work related theft. 
Table 2: (Continued)

\begin{tabular}{l} 
Theme Category \\
\hline The codeine feeling \\
1. Physical reasons for initial use centred on physical pain (migraine, dental, back, menstrual, joint, \\
postoperative, child birth). \\
2. Recognition of appreciation and 'liking' the effect of codeine, which contributed to development of \\
inappropriate 'misuse' patterns for other emotive reasons. \\
3. Low initial use for recreational intoxication purposes. \\
4. Initial perspectives around the codeine intoxication feeling centred on its euphoric, warm, fuzzy \\
feeling, pleasurable effect and ability to assist sleep. \\
5. Use generally occurred privately and at home (to a lesser extent at work). \\
6. Buffer mechanism or 'crutch' in negotiating daily tasks and stressors. \\
7. Codeine's capacity to reduce stress and enhance relaxation. \\
8. Codeine to enhance motivation and confidence within normal daily activity. \\
9. Development of daily use appeared to cement codeines psychological role in the reduction of and \\
distancing from depression and anxiety. \\
10. Legitimised use in serving a perceived therapeutic need and availability in pharmacies appeared to \\
enhance user solitary and covert habitual use. \\
11. Despite generally consuming codeine products in private homes, commonly alone, codeine \\
intoxication assisted with social communication. \\
12. Low reporting of partner use. \\
13. On consistent use over time codeine intoxication was described as changing from having a sedative \\
numbing effect to energising the user. \\
14. Codeine addiction contributing to depression itself.
\end{tabular}

The daily routine

1. Daily use progressed within several weeks and grounded in the users' appreciation of the opiate effect and rising tolerance.

2. Thought processes around consumption of codeine on awakening.

3. Use characterised by intense craving and need to consume in order to 'feel normal' and operate throughout the day.

4. Maximum daily doses ranging between 24 and 115 tablets/day (e.g. between three and four boxes of Nurofen $+{ }^{\circledR}$ ).

5. High dose daily consumption occurring within 6-12 months.

6. Staggered use of high dose amounts throughout the day.

7. Consciously never exceeding over the recommended daily guidelines for use but misusing products over the long term.

8. Financial and time related cost in supporting a daily 'codeine habit'

Acute and chronic side effects

Social isolation

Withdrawal and dependence
1. Reported acute side effects centred on opiate urticarial itching, distorted vision and respiratory depression.

2. Chronic health consequences centred on weight loss, rebound headache, nausea, constipation, liver, bowel and kidney failure, anaemia, seizures, ulcers and swollen stomach.

3. Symptoms of withdrawal centred on emesis, diarrhoea, sweating, agitation, insomnia, seizures and cramps.

1. Loss of social support networks due to the isolating and pre-occupating nature of codeine dependence.

2. Codeine dependence itself negatively impacted on family relationships, contributing to child neglect and ability to sustain employment.

3. Trauma centring on abuse, loss of children, spouses and family homes.

4. Failed attempts to cease use additionally contributed to family dysfunction.

1. Craving and unpleasant withdrawal symptoms supported continued use.

2. Fears around existing pain conditions underpinned difficulties in ceasing use.

3. Consumption of sufficient codeine to keep withdrawals at bay in order to sustain normal social functioning and employment.

4. Necessity to develop a new daily routine and alternate coping mechanisms underpinned difficulties in self-detoxing.

5. Self-detoxification attempts common but unsuccessful, and often resulting in greater amounts consumed when resuming use. 
Table 2: (Continued)

\begin{tabular}{ll}
\hline Theme & Category \\
\hline $\begin{array}{l}\text { Help-seeking and } \\
\text { treatment experiences }\end{array}$ & 6. $\begin{array}{l}\text { 1. Help-seeking efforts overall positive and grounded in pharmacist and treatment service intervention. } \\
\text { detoxification. }\end{array}$ \\
3. Barriers to treatment access and retention centred on stigma and labelling as drug addict, particularly \\
in the case of supervised methadone consumption in pharmacies. \\
4. Supportive medical care and a slow approach to tapering of codeine products themselves, or \\
substitution agents to avoid unpleasant withdrawals optimal. \\
5. Relapse with codeine phosphate tapering universal due to lack of effect on cravings, and instances of \\
'topping up' with Nurofen $+{ }^{\circledR}$. \\
6. Difference in effect between prescribed codeine phosphate and Nurofen $+{ }^{\circledR}$ complicated successful \\
withdrawal attempts. \\
7. Adopting a new daily routine was deemed important in stabilisation. \\
8. Suboxone ${ }^{\circledR}$ viewed very positively in removal of craving and withdrawal effects. \\
9. Integrated pharmacy led detoxification can offer an alternative to accessing mainstream drug \\
treatment centres.
\end{tabular}

\section{Results}

\section{Profile and product preferences}

A total of $57 \%(n=12)$ of the sample were female and $43 \%(n=9)$ male. Participants ranged from 26 to 62 years old (mean age $=39$ ) with $71 \%(n=15)$ aged between 30 and 49 years. A total of $52 \%(n=11)$ of participants were unemployed. A total of 15 participants admitted to using codeine within the last 12 months and with a majority scored 10 or above $(80 \%$, $n=12)$ in the SDS. A total of 18 of the 20 participants reported codeine-based medications (e.g. Solpadol ${ }^{\circledR}$, Nurofen Plus ${ }^{\circledR}$ or Solpadeine ${ }^{\circledR}$ ) as their primary problematic drug, with the remainder reporting heroin $(n=1)$ and distalgesic $(n=1)$ as primary. A total of $62 \% \quad(n=13)$ reported Nurofen Plus ${ }^{\circledR}$ was their primary drug of use with $67 \%(n=14)$ of participants reporting that they were currently on methadone maintenance treatment and $14 \%(n=3)$ on Suboxone ${ }^{\circledR}$.

Some participants had prior experience of illicit drugs such as heroin, cannabis, cocaine and ecstasy. Opinions around mixing codeine medicines with alcohol and illicit drugs were mixed with regard to desired intoxication outcomes. Many combined codeine with alcohol, particularly at night time.

Every weekend I would combine my codeine use with alcohol and or weed for the extra 'buzz'. I really liked misxing the diazepam with the codeine, it made the high more intense or lasted longer.

Displacement to more serious opioids ('Oxycontin ${ }^{\circledR}$, and heroin) was reported by two participants.
The majority of participants reported preference for misuse of Nurofen Plus ${ }^{\circledR}$, with some displacement during times of unavailability to use of other codeine containing medicines, both over the counter and prescribed (Solpadeine ${ }^{\circledR}$, Feminex $^{\circledR}$, Solpadol ${ }^{\circledR}$, Tylex $^{\circledR}$, Codine ${ }^{\circledR}$ ). A minority reported use of prescribed distalgesic containing codeine.

I have used them [Solpadeine] as a last resort. If I was going to be sick and if I couldn't get Nurofen Plus $®$. Just to stop the withdrawal, I would take the cough syrup and the Solpadeine.

The effect of Nurofen Plus ${ }^{\circledR}$ was described by many participants as optimal for intoxication purposes. Solpadeine ${ }^{\circledR}$ was observed to contain too much caffeine, with unpleasant symptoms on excessive use while Feminex ${ }^{\circledR}$ was reported to cause nausea. Consumption of tablets was favoured.

\section{Awareness of habit forming use and harm}

The majority of participants were not aware of the addictive potential of codeine containing medicines and the harms related to additives such as ibuprofen and paracetamol. A minority (two) reported reading the product information leaflet. Two participants were health professionals and were aware of addictive potential and related harms.

You were never told. Now you know that it's not the codeine that is the problem, it's the Ibuprofen that is the problem. 
One participant commented on a lack of public awareness and televised product marketing as painkiller by companies.

I really don't think people know the danger of codeine, but the ads are back on the television now.

The majority of participants commented on the need for greater information provision around use, and risks of misuse from prescribing doctors relating to codeine containing medicines.

If it was explained to me properly by the doctor what the risks could be, I may not have even gone down that road in the first place, the predictability and how quickly it would take for you to get addicted on it. I think patients should be told more about what the symptoms are and what can happen.

A minority of participants were aware of intoxication potential of codeine containing medicines for recreational purposes, but were unaware of addiction risk.

My cousin said that we could get it [codeine] from Nurofen Plus ${ }^{\circledR}$. At that time we didn't know it was addictive.

Nearly all participants reported consulting the internet to learn more about which products contained codeine when actively misusing. In terms of optimising the effect and reduction of harm by removal of additives, two participants reported tablet splicing of Nurofen Plus ${ }^{\circledR}$ and cold water extraction. One reported eating food before consumption of large amounts of tablets.

The best part was that the paracetemol would freeze and all the rest of the water was just golden heaven to drink off.

Despite becoming aware of habit forming use and harm, while actively misusing, participants described denial and were unable to stop.

... to be honest I don't think it would have changed, I knew what was in them, I knew they were addictive.

\section{Negotiating pharmacy sales}

All reported accessing pharmacies as their primary route to securing codeine containing medicines. All described accessing multiple pharmacies in different locations and at various intervals in order to circumvent suspicion. One participant described purchasing over the internet.

... you would have to travel wider, and just go to pharmacies less frequently. An addiction will find a way, there's always a way. When you want something you will always find a way to get it.

Awareness of deception and overt manipulation of pharmacy and medical staff was described.

In my time of addiction, I knew what pharmacist was on and in what place and what name/s I used last time. Addiction teaches you master manipulation. No matter what barriers you build an addicts mind goes far beyond it.

Many described intense discomfort relating to the thought processes of seeking and securing sufficient supplies of codeine containing medicines.

I get so worked up that I am going to get them ... and something pulls me back coz I really don't really want to get them ... I'm emotionally drained.

All participants were aware of PSI 2010 regulation for restricted sale of codeine containing medicines, and employed pre-rehearsed scripts when responding to pharmacist interrogation. Opinions around appearances varied, from 'looking dishevelled and in pain' to appearing "professional" (particularly relating to health professional attire, I would go in there with my nurses uniform and they would never refuse.)

I probably looked like I let go of my appearance, I really didn't care. I got up in the morning and the first thing on my mind was where was I going to go today to get the codeine.

Asking for a female specific codeine containing medicine (Feminexs ${ }^{\circledR}$ ) sometimes secured a successful sale.

When it was men, I would deliberately embarrass them so that I'd get them (Nurofen Plus ${ }^{\circledR}$ ), and if he tried to make me elaborate, he wasn't long blushing and going behind and getting the box for me.

Instances when pharmacy staff recognised the customer, led to purchasing of alternative products or simply leaving the store. Some described asking friends to purchase on their behalf. Pharmacist intervention at point of sale was described by many as triggering thoughts and realisations around misuse.

\section{Alternative sourcing routes}

Alternative methods of sourcing codeine containing medicines centred on diversion via prescriber, street and family routes. Border travel to jurisdictions with less stringent regulations around pharmacy supply was reported by two participants (Spain and Northern Ireland). 
A minority reported accessing surplus codeine containing medicines from friends and family, who did not utilise their repeat script.

Easy enough to come by, I know a friend who got boxes and boxes of it, so she never used to take them.

One participant described street diversion via purchasing from a medical card patient who was in receipt of repeat scripts and not utilising the medicine.

The only place you can get it is from somebody who has a medical card, you can buy it off them. I think they give out medicines too freely on a medical card.

The manipulation of doctors for early and repeat prescriptions was described by several participants.

After going through a monthly prescription in a week, I decided it was time to manipulate some doctors about the "pain" I was in.

Consulting multiple doctors and forging of scripts was described by one participant.

This is when I was cunning and had an addictive mind, I would go to different doctors and I would come with everything and all sorts to get them. I would have 5 or 6 doctors at a time and the scripts I would get, I would copy them at least 5 times.

Two health professionals described stealing at work when having access to secured storage for medicines.

I just thought about codeine all day long. I stole a few from work but soon it was noticed and I never took from work again [nurse].

\section{The codeine feeling}

Physical reasons for initial use centred on physical pain (migraine, dental, back, menstrual, joint, postoperative, child birth). Displacement toward recognition of codeine's pleasurable effect and administration for emotional distress and as a coping mechanism (in some instances postnatal depression) was reported by a majority.

Very quickly it was not enough in the morning to have me floating, feeling euphoric, and care free really. I was numb and I liked that. Nothing stressed me when it worked, codeine filled a void.

Several participants described recognition of appreciation and 'liking' the effect of codeine, which contributed to development of inappropriate 'misuse' patterns for other emotive reasons.

I wasn't expecting the high I got but I was very happy with its effects, it felt like the missing piece to my life. I didn't share my codeine addiction with anyone and I truly believe I became an addict straight after feeling its effects.

One participant described initial use for recreational intoxication purposes.

I used to look forward to it throughout the week

... to treat myself on Friday.

Initial perspectives around the codeine intoxication feeling centred on its euphoric, warm, fuzzy feeling, pleasurable effect and ability to assist sleep. Use generally occurred privately and at home (to a lesser extent at work), and appeared to act as buffer mechanism or 'crutch' in negotiating daily tasks and stressors.

Back then it was simply for the feeling of the drug alone, not for what the drug gave me.

I wasn't in any pain, I would take them to make me in better form, get through the day, just purely for buzz, just to give me a feeling of euphoria.

Comments emphasised codeine's capacity to reduce stress and enhance relaxation, and enhance motivation and confidence within normal daily activity.

For more of a normal feeling, it gave me that sense of de-stressing the body, emotional relief from emotional stress.

Development of daily use appeared to cement codeines psychological role in the reduction of and distancing from depression and anxiety.

I had really no treatment [for depression] but I was totally dependent on the codeine, codeine was my treatment, codeine was my life.

Legitimised use in serving a perceived therapeutic need and availability in pharmacies appeared to enhance user solitary and covert habitual use.

It's very socially acceptable because nobody knows you're doing it.

Despite generally consuming codeine products in private homes, commonly alone, some participants observed how codeine intoxication assisted with social communication.

I wouldn't be sociable if I didn't have them in my system.

Two participants described using with a partner.

We [husband] did do it together but it wasn't a shared thing, it was a need.

With consistent use over time codeine intoxication was described as changing from having a sedative numbing effect to energising the user. 
The drug itself, started to change, it was no longer giving me a downer; it was giving me a booster. That's why it has been so hard; it lifts your spirit.

Codeine addiction was also viewed by some as contributing to depression itself.

It gave me direct depression ... from coming off such a euphoric feeling to just living in the real world.

\section{The daily routine}

Daily use for all progressed within several weeks and grounded in the user's appreciation of the opiate effect and rising tolerance. The majority of participants described thought processes around consumption of codeine on awakening.

I took four and I got a little feeling off of them and I liked it, so then I gradually increased to six and then I just kept going up and up, I just kept taking them all the time.

It slowly expanded pace really rapidly were I was taking three boxes in the morning. I would get all the usual feelings.

Use was characterised by intense craving and need to consume in order to 'feel normal' and operate throughout the day.

I was taking 28 tablets a day. I was taking them to feel normal initially and then the more you take the worse you feel, you end up feeling sick from them but yet you couldn't be without them.

Maximum daily doses were reported to range between 24 and 115 tablets/day (e.g. between three and four boxes of Nurofen Plus ${ }^{\circledR}$ ) and with high dose daily consumption occurring within 6-12 months. Staggered use of high dose amounts throughout the day was common. One participant reported use of 96 tablets of Nurofen Plus ${ }^{\circledR}$ in one go.

I'd take 24 at once and then at lunch time take the other 24 and then in the evening then take the other 24 so that was a ritual of things, gradually I had to take more because I'd take 24 and I wouldn't feel anything.

Some reported consciously never exceeding over the recommended daily guidelines for use but misusing products over the long term, and recognising dependence within 3 months.

Never took more than eight, always within recommended guidelines, but dependent within three months.
Participants commented on financial and time related cost in supporting a daily 'codeine habit'.

It's an expensive little endeavour.

\section{Acute and chronic side effects}

Reported acute side effects centred on opiate urticarial itching, distorted vision and respiratory depression.

We got really itchy, the blotchy skin and the heat flush; the typical Codeine symptoms. As in go to sleep and not breath and then wake up. That's why you can't really take too much. You realise you're so short of breath.

Chronic health consequences centred on nausea, constipation, liver, bowel and kidney failure, anaemia, seizures, ulcers and swollen stomach.

The real physical affect codeine has had on me is bowel failure. I now take 3 different types of medications for my bowels alone.

Several participants described loss of appetite and weight. Rebound headaches were described by half of participants. Symptoms of withdrawal centred on emesis, diarrhoea, sweating, agitation, insomnia, seizures and cramps.

I'd get withdrawals, I'd get very, very agitated and pains in my legs and my arms and my stomach. I'd get blinding head aches and loss of appetite, restlessness, couldn't sleep, I wasn't eating, complete shutdown.

\section{Social isolation}

Loss of social support networks due to the isolating and pre-occupating nature of codeine dependence was described by some participants.

I don't really have friends any more. My friends are gone and it's more a companion addiction. It feels like it has its arm around you. That's how it is for me now. It gives me that sense of security and that's what I'm struggling with at the moment, it's to break that cycle.

Codeine dependence itself was viewed by many as negatively impacting on family relationships, contributing to child neglect and ability to sustain employment. Trauma centring on abuse, loss of children, spouses and family homes were common. Failed attempts to cease use additionally contributed to family dysfunction.

My life has become unmanageable, every penny I have has gone to this tablets, I've lost my job,

I've lost my partner and kids, I had a nice 
home, its actually destroyed my life, it's taken everything, it's taken away my self-respect.

\section{Withdrawal and dependence}

Craving and unpleasant withdrawal symptoms were described as supporting continued use. Fears around existing pain conditions underpinned difficulties in ceasing use for some participants.

It causes horrible dependence, physical and mental dependence. It just destroys your life basically.

Many tried to consume sufficient codeine to keep withdrawals at bay in order to sustain normal social functioning and employment.

I was taking it almost to work because of the withdrawal symptoms. Once I realised I was addicted to something, I realised I'd have to take too much time off work. So it would end up being a vicious circle.

The necessity to develop a new daily routine and in many instances alternate coping mechanisms underpinned difficulties in self-detoxing.

When I used to get up and feel crap, I'll take it and feel instantly better. Now it has become part of my daily routine in my daily life. Trying to break that is really hard.

Self-detoxification attempts were common but unsuccessful, and often more excessive in amounts consumed thereafter. One participant described sourcing street methadone to assist in withdrawals.

I tried to cut down on it, gradually cut down, and then I'd just have a bad day and I'd be straight back up to 24 [tablets].

\section{Help-seeking and treatment experiences}

Help-seeking efforts were overall positive and grounded in pharmacist and treatment service intervention. Realisation of being an addict and loss of employment was described by several as contributing to decisions to attempt detoxification.

The person who becomes addicted to pain killers and over the counter drugs wouldn't necessary see themselves as a drug addict.

There is no difference between a heroin addict and some who's been taking Nurofen Plus ${ }^{\circledR}$. Because at the end of the day, it's not the substance they're treating, it's the person.
Barriers to treatment access and retention centred on stigma and being labelling as a drug addict, particularly in the case of supervised methadone consumption in pharmacies.

It made me feel very shameful and my picture was on the wall with methadone, I just felt very ashamed.

Supportive medical care and a slow approach to tapering of codeine products themselves or substitution agents to avoid unpleasant withdrawals were advised.

If you are taking four boxes it would take you two and a half years to come down. You can't go down too fast, the body needs time to catch up.

For a minority of participants with experience (all unsuccessful) of codeine phosphate withdrawal, the sedative effect of codeine phosphate tapering treatment form contrasted with the Nurofen Plus ${ }^{\circledR}$ energising effect, which patients found complicated their successful detox.

There is a huge difference. The over the counter codeine phosphate makes you feel down and sleepy, Nurofen Plus ${ }^{\circledR}$ makes you the opposite, gives you uplift.

Relapse with codeine phosphate tapering was universal due to lack of effect on cravings, and instances of 'topping up' with Nurofen Plus ${ }^{\circledR}$.

I wouldn't even say I lasted a day or two on that.

I felt a huge overwhelming need, even when

I was taking them [codeine phosphate].

Particularly for those on methadone, while managing unpleasant withdrawals, adopting a new daily routine was deemed important.

I realised that routine is very important in my addiction, so I had to start my own new routines.

Suboxone ${ }^{\circledR}$ in particular was viewed very positively in removal of craving and withdrawal effects.

From the very first day I put a Suboxone in my body, I have no jitter, I have no side effects, I never ever took a codeine since the first day I took Suboxone.

It was a miracle, a door was opened for me, I was able to function, I was on no codeine. I actually walked into the chemist and I apologized to everyone who I had fooled.

Some participants suggested that the pharmacist could support them in tapering down from over the counter codeine containing products, as an alternative to accessing mainstream drug treatment centres. 
I think they would appreciate a different approach, if there was in the middle place where people using over the counter drug could go, instead of going to the main drug centres.

\section{Discussion}

This study presents unique qualitative insights around codeine misuse and dependence within an Irish context following the PSI's regulatory restrictions in 2010 to promote safe supply of non-prescription codeine containing products in Ireland. 'Trustworthiness' of the data (Lincoln \& Guba, 1985) is promoted by verification of extensive similarities across the lived experience of participants, along with horizontal and vertical consistency in the interpretation of the data, and partial phenomenological psychological reduction (Karlsson, 1995).

The study builds on findings reported in earlier qualitative studies with codeine dependents in the United Kingdom (Cooper, 2011, 2013a), Australia (Nielsen et al. 2010, 2011, 2013) and active online drug users (Van Hout, 2015). Given the covert nature of this issue, confounded by withdrawals, emotional distress and potential for serious co-morbidity, this study presents novel and meaningful illustration of the codeine misuse phenomenon, particularly within the Irish context. Multiple routes to access centred on the easy availability of codeine-based products within pharmacies, when prescribed via repeat or through the forging of scripts, over the counter and diversionary means. All contributed to the misuse of codeine in individuals largely unaware of potential for habit forming use, craving and withdrawals. Two way displacements between prescribed codeine for physical pain management and over the counter sourcing were observed and similar to that illustrated in Cooper's study in the United Kingdom (2013a). Similar to extant research (Inciardi et al. 2009, 2010; Wilsey et al. 2010; Hamer et al. 2013) online sourcing of codeine rarely occurred in preference for pharmacies, and prescribers.

This study supports the distinction of three broad categories of codeine misuse identified in Australia (Nielsen et al. 2010) and the United Kingdom (Cooper, 2011): (1) use which never exceeds the maximum recommended dose, but in terms of duration and nature of use meets criteria for dependence, (2) consumption of slightly higher than the recommended dose (for therapeutic or non-therapeutic reasons) and (3) consumption of doses which substantially exceed recommended doses (generally in the context of serious opioid dependence). Daily doses were described as over the recommended daily dose of $240 \mathrm{mg}$, and higher than other studies reporting ranges of 21-65 tablets daily (Brands et al. 2004; McAvoy et al. 2011; Van Hout, 2015). Adverse health consequences on sustained long-term codeine use were similar to those reported earlier in the literature, with withdrawalbased medication overuse headache (Katsarava \& Jensen, 2007; Bendtsen et al. 2012) common.

The phenomenon of codeine misuse appeared closely situated within the 'blurring' of therapeutic self-medication for legitimate medical reasons (chronic pain), and misuse for iatrogenic dependence (Sproule et al. 1999; Nielsen et al. 2010; Hamer et al. 2013; Roussin et al. 2013; Nielsen et al. 2014), alongside individual difficulties in self-identifying problematic use along their own trajectory of use (Pates et al. 2002; Nielsen et al. 2010). Of note were the invisible and covert characteristics of dependent use, combined with social isolation over time. Use of codeine products was described as facilitating the individuals' capacity to operate quasi-normally within life and work stressors and relationships. The research supports that individuals dependent on codeine largely differ from other population's dependent on prescription opioids by higher employment rates (Nielsen et al. 2011, 2014). Recognition of needing help for codeine dependence or identification as 'drug addict' (Dobbin \& Tobin, 2008; Nielsen et al. 2010; Cooper, 2013a, 2013b) occurred when adverse effects and socio-economic problems relating to codeine misuse became intolerable. Help seeking was positive, despite some reporting of stigma relating to methadone maintenance treatment. Use of Suboxone (buprenorphine and naloxone) showed promise in stabilisation and recovery.

\section{Conclusion}

This study highlights the unique and hidden nature of the codeine misuse phenomenon and with trajectories of habit forming use and dependence particularly underpinned by presence of emotional distress and self-medication. Interventions for referral, treatment and management of codeine misuse remain limited given it's heterogeneous nature, over the counter availability and lack specificity for this distinct group of opiate dependents despite extrapolation from extant evidence-based opioid policies and protocols (Myers et al. 2003; Thekiso \& Farren, 2010; Cooper, 2011, 2013a; Reed et al. 2011). Access to existing treatment systems is hampered by stigma and poor consideration of needs, with pathways and outcomes complicated by requirements for the co-existing management of physical pain (Dobbin \& Tobin, 2008; Fishbain et al. 2008; Reed et al. 2011). There is a public health and regulatory imperative to develop proactive responses tackling public availability of codeine containing medicines, risk minimisation in consumer self-treatment 
for physical and emotional pain, need for enhanced patient awareness of habit forming use and its consequences, and continued health professional screening and pharmacovigilence (Casati et al. 2012; Cooper, 2013b; Agnich et al. 2013; Van Hout et al. 2014).

\section{Financial Support}

The research leading to these results has received funding from the European Community's Seventh Framework Programme FP7/2007-2013 under grant agreement no 611736.

\section{Conflicts of Interest}

None.

\section{Ethical Standards}

The authors assert that all procedures contributing to this work comply with the ethical standards of the relevant national and institutional committee on human experimentation with the Helsinki Declaration of 1975, as revised in 2008. The study protocol was approved by the institutional review board of each participating institution. Written informed consent was obtained from all participating patients.

\section{References}

Acocella CM (2005). Using diaries to assess non prescription drug use among university students. Journal of Drug Education 35, 267-274.

Agaba EI, Agaba PA, Wigwe CM (2004). Use and abuse of analgesics in Nigeria: a community survey. Nigerian Journal of Medicine 13, 379-382.

Agnich L, Stogner JM, Miller BL, Marcum C (2013). Purple drank prevalence and characteristics of misusers of codeine cough syrup mixtures. Addictive Behaviors 38, 2445-2449.

Agyapong VIO, Singh K, Savage M, Thekiso BT, Finn M, Farren CK, McLoughlin DM (2013). Use of codeinecontaining medicines by Irish psychiatric in-patients before and after regulatory limitations on their supply. Irish Journal of Psychological Medicine 30, 7-12.

Akram G, Roberts K (2003). Pharmacists' management of overthe-counter medi-cation requests from methadone patients. Journal of Substance Use 8, 215-222.

Albsoul-Younes A, Wazaify M, Yousef AM, Tahaineh L (2010). Abuse and misuse of prescription and non prescription drugs sold in community pharmacies in Jordan. Substance Use and Misuse 45, 1319-1329.

Allotey P, Reidpath DD, Elisha D (2004). "Social medication" and the control of children: a qualitative study of overthe-counter medication among Australian children. Pediatrics 114, e378-e383.

Babalonis S, Lofwall MR, Nuzzo PA, Siegel AJ, Walsh SL (2013). Abuse liability and reinforcing efficacy of oral tramadol in humans. Drug and Alcohol Dependence 129, 116-124.
Barrett SP, Meisner JR, Stewart SH (2008). What constitutes prescription drug misuse? Problems and pitfalls of current conceptualizations. Current Drug Abuse Reviews 1, 255-262.

Bendtsen L, Birk S, Kasch H, Aegidius K, Sørensen PS, Thomsen LL, Poulsen L, Rasmussen MJ, Kruuse C, Jensen R, Danish Headache Society (2012). Reference programme: diagnosis and treatment of headache disorders and facial pain. Danish Headache Society. Journal of Headache and Pain 13, 1-29.

Brands B, Blake J, Sproule B, Gourley D, Busto U (2004). Prescription opioid abuse in patients presenting for methadone maintenance treatment. Drug and Alcohol Dependence 73, 199-207.

Casati A, Sedefov R, Pfeiffer-Gerschel T (2012). Misuse of medicines in the European union: a systematic review of the literature. European Addiction Research 18, 228-245.

Cohen DP, Unoh E, Barry H, O'Connor JJ (2009). Codeine misuse among service users on a methadone treatment programme. Irish Journal of Medical Science 179, 465.

Comments on the Reported Statistics on Narcotic Drugs Austria: 73-93 - International Narcotics Controls Board (INCB) (https:/ / www.incb.org/). Accessed October 2013.

Cooper RJ (2011). Respectable addiction - a qualitative study of over the counter medicine abuse in the UK. Sheffield, UK: School of Health and Related Research (ScHARR), University of Sheffield.

Cooper RJ (2013a). I can't be an addict. I am.' Over-the-counter medicine abuse: a qualitative study. BMJ Open Online 3, e002913.

Cooper RJ (2013b). Over-the-counter medicine abuse: a review of the literature. Journal of Substance Use 18, 82-107.

Derry S, Karlin SM, Moore RA (2013). Single dose oral ibuprofen plus codeine for acute postoperative pain in adults. The Cochrane Database Systematic Review 3, CD010107.

Dobbin M, Tobin C (2008). Over-the-Counter (OTC) Ibuprofen/ Codeine Analgesics: Misuse and Harm. Drugs Policy and Services Branch, Department of Human Services: Melbourne, Vic, Australia.

Elwood W (2001). Sticky business: patterns of procurement and misuse of pescription cough syrup in houston. Journal of Psychoactive Drugs 33, 121-133.

Fishbain DA, Cole B, Lewis J, Rosomoff HL, Rosomoff RS (2008). What percentage of chronic non malignant pain patients exposed to chronic opioid analgesic therapy develop abuse/addiction and/or aberrant drug-related behaviors? A structured evidence-based review. Pain Medicine 9, 444-459.

Ford JA (2009). Misuse of over-the-counter cough or cold medications among adolescents: prevalence and correlates in a national sample. Journal of Adolescent Health 44, 505-507.

Fredheim OMS, Skurtveit S, Moroz A, Breivik H, Borchgrevink PC (2009). Prescription pattern of codeine for non-malignant pain: a pharmacoepidemiological study from the Norwegian Prescription Database. Acta Anaesthesiological Scandinavica 53, 627-633.

Frei MY, Nielsen S, Dobbin MD, Tobin CL (2010). Serious morbidity associated with misuse of over-the-counter codeine-ibuprofen analgesics: a series of 27 cases. Medical Journal Australia 193, 294-296. 
Gossop M, Darke S, Griffiths P, Hando J, Powis B, Hall W, Strang J (1995). The Severity of Dependence Scale (SDS): psychometric properties of the SDS in English and Australian samples of heroin, cocaine and amphetamine users. Addiction 90, 607-614.

Hamer A, Spark J, Wood P, Roberts E (2013). The upscheduling of combination analgesics containing codeine: the impact on the practice of pharmacists. Research in Social and Administrative Pharmacy 10, 669-678.

Giorgi A (1997). The theory, practice, and evaluation of the phenomenological method as a qualitative research procedure. Journal of Phenomenological Psychology 28, 235-260.

Husserl E (1970). Logical Investigation. New York: Humanities Press.

INCB (International Narcotics Controls Board) (2012). Comments on the Reported Statistics on Narcotic Drugs Austria, 73-93 (https://www.incb.org/). Accessed October 2013.

Inciardi JA, Surratt HL, Cicero TJ, Rosenblum A, Ahwah C, Bailey JE, Dart RC, Burke JJ (2010). Prescription drugs purchased through the internet: who are the end users? Drug and Alcohol Dependence 110, 21-29.

Ingelman-Sundberg M, Sim SC, Gomez A, RodriguezAntona C (2007). Influence of cytochrome P450 polymorphisms on drug therapies: pharmacogenetic, pharmacoepigenetic and clinical aspects. Pharmacology and Therapeutics 116, 496-526.

Johansson BA, Berglund M, Hanson M, Pohlen C, Persson I (2003). Dependence on legal psychotropic drugs among alcoholics. Alcohol and Alcoholism: International Journal of the Medical Council on Alcoholism 38, 613-618.

Karlsson G (1995). Psychological Qualitative Research from a Phenomenological Per-Spective. Almqvist \& Wiksell International: Stockholm, Sweden.

Katsarava Z, Jensen R (2007). Medication-overuse headache: where are we now? Current Opinion in Neurology 20 326-330.

Kelly LE, Madadi P (2012). Is there a role for therapeutic drug monitoring with codeine? Therapeutic Drug Monitoring 34, 249-256.

Lam CM, Shek D (2006). A qualitative study of cough medicine abuse among Chinese young people in Hong Kong. Journal of Substance Abuse 11, 233-244.

Lao YZ, Jiang ZY, Tong ZS, Pang ZT, Xu JX (2010). Clinical features and defense styles in patients with cough medicine abuse. Medical Journal of Chinese People's Health 22, 272-274.

Lincoln YS, Guba EG (1985). Naturalistic Inquiry. Sage: Beverly Hills, CA.

Manchia M, Alda M, Clakin C (2013). Repeated erythromycin/codeine-induced psychotic mania. Clinical Neuropharmacology 36, 177-178.

Mattick RP, Kimber J, Breen C, Davoli M (2008). Buprenorphine maintenance versus placebo or methadone maintenance for opioid dependence. Cochrane Database of Systematic Reviews $\mathbf{2}$.

Maxwell JA (1992). Understanding and validity in qualitative research. Harvard Educational Review 62, 279-301.

McAvoy BR, Dobbin M, Tobin C (2011). Over-the-counter codeine analgesic misuse and harm: characteristics of cases in Australia and New Zealand. New Zealand Medical Journal 124, 29-33.

Myers B, Siegfried N, Parry CD (2003). Over-the-counter and prescription medicine misuse in Cape Town - findings from specialist treatment centres. South African Medical Journal 93, 367-370.

Nielsen S, Bruno R, Carruthers S, Fischer J, Lintzeris N, Stoove M (2008). Investigation of Pharmaceutical Misuse Amongst Drug Treatment Clients. Turning Point Alcohol and Drug Centre: Melbourne, Australia.

Nielsen S, Cameron J, Lee N (2011). Characteristics of a nontreatment-seeking sample of over-the-counter codeine users: implications for intervention and prevention. Journal of Opioid Management 7, 363-370.

Nielsen S, Cameron J, Pahoki S (2010). Over the Counter Codeine Dependence. Turning Point Drug and Alcohol Centre: Vic, Australia.

Nielsen S, Cameron J, Pahokia S (2013). Opportunities and challenges: Over-the-counter codeine supply from the codeine consumer's perspective. International Journal of Pharmacy Practice 21, 161-168.

Nielsen S, Murnion B, Dunlop A, Degenhardt L, Demirkol A, Muhleisen P, Lintzeris N (2014). Comparing treatmentseeking codeine users and strong opioid users: findings from a novel case series. Drug and Alcohol Review 34, 304-311.

Nielsen S, Roxburgh A, Bruno R, Lintzeris N, Jefferson A, Degenhardt L (2015). Changes in non-opioid substitution treatment episodes for pharmaceutical opioids and heroin from 2002 to 2011. Drug Alcohol Depend 149, 212-219.

Pates R, McBride AJ, Li S, Ramadan R (2002). Misuse of overthe-counter medicines: a survey of community pharmacies in a South Wales health authority. Pharmaceutical Journal 268, 179-182.

Peters R, Yacoubian GS, Rhodes W, Forsythe KJ, Bowers KS, Eulian VM, Mangum CA, O'Neal JD, Martin Q, Essien EJ (2007a). Beliefs and social norms about codeine and promethazine hydrochloride cough syrup (CPHCS) use and addiction among multi-ethnic college students. Journal of Psychoactive Drugs 39, 277-282.

Peters RJ, Williams M, Ross MW, Atkinson J, Yacoubian GS (2007b). Codeine cough syrup use among African-American crack cocaine users. Journal of Psychoactive Drugs 39, 97-102.

Peters RJ, Amos C, Meshack A, Savage C, Sinclair MM, Williams LT, Markham C (2007c). Codeine cough syrup use among sexually active, African-American high school youths: why southern males are down to have sex. The American Journal on Addictions 16, 144-145.

Peters RJ, Kelder SH, Markham CM, Yacoubian GS, Peters LA, Ellis A (2003). Beliefs and social norms about codeine and promethazine hydrochloride cough syrup (CPHCS) onset and perceived addiction among urban Houstonian adolescents: an addiction trend in the city of lean. Journal of Drug Education 33, 415-425.

Reed K, Bond A, Witton J, Cornish R, Hickman M, Strang J (2011). The Changing Use of Prescribed Benzodiazepines and Z-Drugs and of Over-the-Counter Codeine-Containing Products in England: A Structured Review of Published English and 
International Evidence and Available Data to Inform Consideration of the Extent of Dependence and Harm. The National Addiction Centre, Kings College London and School of Social and Community Medicine, University of Bristol, United Kingdom: London and Bristol.

Robinson GM, Robinson S, McCarthy P, Cameron C (2010). Misuse of over-the-counter codeine-containing analgesics: dependence and other adverse effects. New Zealand Medical Journal 123, 59-64.

Romach MK, Sproule BA, Sellers EM, Somer G, Busto UE (1999). Long-term codeine use is associated with depressive symptoms. Journal of Clinical Psychopharmacology 19, 373-376.

Roumie CL, Griffin MR (2004). Over-the-counter analgesics in older adults, a call for improved labelling and consumer education. Drugs and Aging 21, 485-498.

Roussin A, Bouyssi A, Pouche L, Pourcel L, Lapeyre-Mestre M (2013). Misuse and dependence on non-prescription codeine analgesics or sedative $\mathrm{H} 1$ antihistamines by adults: a crosssectional investigation in France. PLoS One 8, e76499.

Shek DT, Lam CM (2006). Adolescent cough medicine abuse in Hong Kong: implications for the design of positive youth development programs in Hong Kong. International Journal of Adolescent Medicine and Health 18, 493-503.

Shek DTL, Lam CM (2008). Beliefs about cough medicine abuse among Chinese young people in Hong Kong. Social Behavior and Personality 36, 135-144.

Skurtviet S, Faru K, Borchgrevink P, Handal M, Fredheim O (2011). To what extent does a cohort of new users of weak opioids develop persistent or probable problematic opioid use? International Association for the Study of Pain 152, 1555-1561.

Sproule BA, Busto UE, Somer G, Romach MK, Sellers EM (1999). Characteristics of dependent and nondependent regular users of codeine. Journal of Clinical Psychopharmacology 19, 367-372.

Sweileh WM, Arafat RT, Al-Khyat LS, Al-Masri DM, Jaradat NA (2004). A pilot study to investigate over-the-counter drug abuse and misuse in Palestine. Saudi Medical Journal 25, 2029-2032.

Tang AK, Tang WK, Liang HJ, Chan F, Mak SC, Ungvari GS

(2012). Clinical characteristics of cough mixture abusers referred to three substance abuse clinics in Hong Kong: a retrospective study. East Asian Archives of Psychiatry 22, 154-159.

Thekiso B, Farren C (2010). Over the counter' (over the counter) opiate abuse treatment. Irish Journal of Psychological Medicine 27, 189-191.

Tobin C, Dobbin M, McAvoy B (2013). Regulatory responses to over the-counter codeine analgesic misuse in Australia, New Zealand and the United Kingdom. Australian and New Zealand Journal of Public Health 37, 483-488.

Tremlett M, Anderson BJ, Wolf A (2010). Pro-con debate: is codeine a drug that still has a useful role in pediatric practice? Paediatric Anaesthesia 20, 183-194.

UNODC (2011). The non medicinal use of prescription drugs. Discussion paper. United Nations Publication: Vienna.

UNODC (2013). World drug report 2013. United Nations Publication: Vienna.

Van Hout MC (2015). Nod and wave: an internet study of the codeine intoxication phenomenon. International Journal of Drug Policy 26, 67-77.

Van Hout MC, Bergin M, Foley M, Rich E, Rapca AI, Harris R, Norman I (2014). A Scoping review of codeine use, misuse and dependence, final report. CODEMISUSED Project European Commission 7th Framework Programme, EU. Brussels.

Wilkinson D, Thelwall M (2011). Researching personal information on the public web: methods and ethics. Social Science Computer Review 29, 387-401.

Wilsey BL, Fishman SM, Gilson AM, Casamalhuapa C, Baxi H, Zhang H, Li CS (2010). Profiling multiple provider prescribing of opioids, benzodiazepines, stimulants, and anorectics. Drug and Alcohol Dependence 112, 99-106.

Wilson KM, Singh P, Blumkin AK, Dallas L, Klein JD (2010). Knowledge gaps and misconceptions about over-thecounter analgesics among adolescents attending a hospitalbased clinic. American Academy of Pediatrics 10, 228-232.

Yang Y, Yuan QY (2008). Investigation and analysis on personalities of male - codeine phosphate addicts by MMPI. Chinese Journal of Drug Abuse Prevention and Treatment 14, 143-145.

Zhou S (2009). Polymorphism of human cytochrome P450 2D6 and its clinical significance. Part 1. Clinical Pharmacokinetics 48, 689-723. 